\title{
A "experiência precoce da punição": justiça juvenil, adolescentes em conflito com a lei e instituições de internamento
}

\author{
The "precocious experience of punishment": juvenile justice, \\ teenagers in conflict with the law and internment institutions
}

\section{Marcos César Alvarez ${ }^{a}$, Luiz Cláudio Lourençob e Juliana Tonche}

No Brasil, ainda na atualidade, o destino social de crianças e de jovens pobres oscila entre as dimensões da proteção e dos direitos, por um lado, e da punição e do controle social, por outro. Durante grande parte do século XX, as legislações voltadas para os assim chamados menores equacionaram as respostas institucionais em torno da alternativa entre "trabalho precoce" ou "criminalidade precoce" (Alvarez, 1989). O Estatuto da Criança e do Adolescente (ECA, lei n 8.069/90) buscou romper com esse tratamento "menorista" da questão, ao afirmar sobretudo os direitos de crianças e adolescentes e buscar a efetiva inclusão no âmbito da cidadania. Mas a mudança da legislação não implicou necessariamente numa total ruptura com as práticas precedentes, com as formas de rotulação e de estigmatização dirigidas a crianças e adolescentes, a maioria negros e pardos, geralmente moradores de bairros periféricos dos grandes centros metropolitanos do país.

Este dossiê da Plural, revista do Programa de Pós-Graduação em Sociologia da Universidade de São Paulo, apresenta discussões que justamente aprofundam aspectos daquilo que Sérgio Adorno caracterizou como "a experiência precoce da punição" (ADORNo, 1993). A proposta consistiu em acolher reflexões e pesquisas acerca das características da Justiça Juvenil no Brasil, das mudanças legais e institucionais e das práticas e dos discursos que conformam as dimensões coletivas dessa experiência no país.

No debate local, Tobias Barreto foi um pioneiro desta discussão, com seu livro Menores e Loucos, cuja primeira edição é de 1884 (BARRETo, 1926), e no qual discute a questão da legislação criminal da época referente ao "menor". Nas

a Formado em Ciências Sociais pela Universidade de São Paulo, mestre, doutor e livre-docente pela mesma instituição. Professor do Departamento de Sociologia da USP e pesquisador do Núcleo de Estudos da Violência, NEV/USP.

b Professor do Departamento de Sociologia e do Programa de Pós-Graduação em Ciências Sociais da Universidade Federal da Bahia.

c Formada em Ciências Sociais pela UFSCar, mestre (UFScar) e doutora (USP) em Sociologia. Atualmente é pós-doutoranda do Departamento de Sociologia da USP. 
décadas seguintes, será sobretudo no âmbito do Direito que tal tema será debatido. Apenas a partir da segunda metade do século XX é que pesquisas como a realizada pelo CEBRAP, e que resultou no livro $A$ criança, o adolescente e a cidade (CEBRAP, 1972), começaram a deslocar o que ficara anteriormente conhecido como "o problema do menor" de um ponto de vista estritamente jurídico para uma discussão sociológica que levasse em conta os mecanismos sociais de marginalização e de estigmatização que acabavam por construir essa própria figura social.

Desde então, a bibliografia crítica sobre o tema tem crescido significativamente, envolvendo áreas como o Serviço Social, a Psicologia e as demais Ciências Sociais e explorando múltiplas direções de investigação, que o presente dossiê buscou em parte contemplar. Tanto em âmbito internacional quanto local, a questão da constituição, das características e do papel da assim chamada Justiça Juvenil tem sido investigada, sobretudo em termos da tensão entre os ideais de recuperar e de punir, mais expressiva neste tipo de justiça. Tal questão é discutida na entrevista que compõe o dossiê, intitulada A teoria da "Racionalidade Penal Moderna" e os desafios da Justiça Juvenil, realizada com o professor Álvaro Pires, que foi entrevistado por Bruna Gisi, Juliana Tonche, Marcos César Alvarez e Thiago Oliveira.

Pires é professor do Departamento de Criminologia da Universidade de Ottawa, Canadá, onde, além de lecionar há mais de trinta anos, possui também uma Cátedra de Pesquisas em Tradições Jurídicas e Racionalidade Penal, subvencionada pelo governo canadense. Com uma vasta produção, que se situa na intersecção entre a Sociologia, a Criminologia e o Direito, e tendo formado, neste período, inúmeros pesquisadores e docentes, o professor Pires é referência para todos aqueles que se dedicam a tentar compreender as modernas formas de punição. Em suas palavras, diz que faz uma Sociologia do Direito criminal com o Direito criminal, em oposição a uma Sociologia do Direito Criminal sem o Direito.

$\mathrm{Na}$ entrevista apresentada neste dossiê, ele discorre sobre sua trajetória profissional, destacando autores cujas influências foram decisivas para o desenvolvimento de sua agenda de pesquisas, além de contar como foi seu encontro pessoal com o filósofo Michel Foucault. Ele igualmente desenvolve aquela que é talvez sua mais conhecida contribuição para este campo de estudos, a chamada teoria da Racionalidade Penal Moderna, e, a partir dela, tece uma série de considerações sobre os desafios que envolvem a produção de um direito voltado para a infância e a juventude.

Os artigos aprovados neste dossiê viabilizam um diagnóstico multifacetado que faz jus à complexidade do problema em questão, quer explorando, em perspectiva histórica, a emergência e reprodução das leis, instituições e práticas nesse 
âmbito, quer os desdobramentos posteriores ao ECA, como a execução e os efeitos das medidas de internação e protetivas.

Diversas pesquisas no Brasil se voltaram para a história da justiça juvenil e das políticas na área no país e seus efeitos múltiplos, inclusive em termos de assujeitamento de crianças e de adolescentes considerados "abandonados", e que tiveram suas vidas capturadas por práticas e instituições voltadas ao controle dos “menores" (Passetti, 1982; Alvarez, 1989; Rizzini, 2004, entre outros). O primeiro artigo do dossiê, intitulado Menoridade e periculosidade: intersecções e assujeitamentos, de Alessandra Teixeira e Fernanda Emy Matsuda, retoma esta linha de investigação de forma inovadora. Baseado em pesquisa documental, o artigo discute o entrecruzamento entre as categorias "menoridade" e "periculosidade" entre os anos 1920 e 1950 no estado de São Paulo. Mostra como os discursos médico-legal e criminológico da época, a partir destas categorias, possibilitaram o efetivo ingresso da menoridade num projeto de controle policial e institucional mais amplo, violento e assujeitador, empurrando paulatinamente o "menor abandonado" para o destino da delinquência. O artigo, assim, segue os desdobramentos legais e institucionais posteriores à década de 1920, ao analisar o Código Penal de 1940, os Relatórios Policiais referentes às décadas de 1930 e 1940, a criação do Serviço de Abrigo e Triagem (SAT), subordinado ao Juizado de Menores, em 1953, e o Recolhimento Provisório de Menores (RPM) e o Centro de Observação Feminina (COF), no ano seguinte.

Como afirmado anteriormente, o ECA buscou romper com essas formas anteriores de assujeitamento que encontravam suporte tanto na legislação quanto nos saberes e práticas institucionais. O Estatuto, no entanto, estabeleceu as medidas socioeducativas de internação para adolescentes autores de atos infracionais, o que aponta novamente para um duplo caráter no tratamento do problema: por um lado, pedagógico, por outro, ainda punitivo, já que a possibilidade de internação permanece colocada (PAUla, 2011). Pesquisas recentes têm se voltado para o estudo desta tensão no âmbito da execução da medida socioeducativa de internação, para o modo como a internação é representada e praticada no cotidiano institucional. $\mathrm{O}$ artigo seguinte do dossiê, de Bruna Gisi de Almeida, A produção do fato da transformação do adolescente: uma análise dos relatórios utilizados na execução da medida socioeducativa de internação, segue por essa trilha.

Em pesquisa realizada com as instituições responsáveis pela execução da medida de internação em São Paulo, a autora observa uma questão específica: o processo de construção da decisão sobre o tempo de duração da internação de adolescentes, autores de atos infracionais, a partir dos relatórios produzidos pelas 
equipes técnicas nas unidades de internação para adolescentes, documentos que justamente fundamentam tal decisão judicial sobre a liberação do adolescente. $O$ acesso a esse material documental foi possível a partir de consulta ao acervo institucional da Fundação CASA que, no estado de São Paulo, arquiva os prontuários de todos os adolescentes que passaram por medida de internação. Em termos teóricos e metodológicos, o trabalho é instigante ao analisar os documentos a partir de uma abordagem particular - da etnometodologia - que aborda os relatórios das unidades de internação tendo em vista o contexto prático de sua elaboração no interior das atividades rotineiras dessas organizações voltadas aos adolescentes. Deste modo, não se ignora o trabalho interpretativo dos atores responsáveis pela produção dessa documentação e o uso de categorias e de teorias de "senso comum" que buscam produzir relatos coerentes dos acontecimentos. O resultado da investigação reforça o papel central que os relatórios adquirem no processo de execução da medida, tendo em vista a indeterminação do tempo de duração da internação e o pressuposto de que são as alterações no indivíduo que fundamentam a decisão sobre o encerramento ou não da medida.

Igualmente voltado para o estudo da execução da medida socioeducativa de internação e para os agentes socioeducativos, o trabalho intitulado No fio da navalha: efeitos da masculinidade e virilidade no trabalho de agentes socioeducativos, com autoria de Juliana Vinuto, Leandro de Oliveira Abreo e Hebe Signorini Gonçalves, discute a pouca explorada questão da masculinidade e da virilidade no cotidiano do trabalho desses agentes. A pesquisa desloca o foco dos adolescentes em cumprimento de medida socioeducativa em favor dos profissionais que atuam nesse processo, muitas vezes lembrados apenas quando existem denúncias de agressões ou violações de direitos, e igualmente para o trabalho diário realizado nas instituições, permeado por tensões decorrentes da dupla exigência de educar e ao mesmo tempo conter os indivíduos em estabelecimentos ainda de tradição disciplinar. A pesquisa empírica que sustenta a reflexão foi realizada especificamente com agentes socioeducativos do Departamento Geral de Ações Socioeducativas (DEGASE), órgão que executa as medidas socioeducativas de semiliberdade e internação no estado do Rio de Janeiro, tendo por material as narrativas dos próprios agentes acerca de seu cotidiano. Os resultados alcançados apontam que a questão da virilidade, hegemônica na sociedade mais ampla, transmuta-se em ferramenta de sobrevivência em unidades socioeducativas de internação, locais de permanente tensão e conflito. Entretanto, ao adotar posturas viris por longos períodos, os agentes acabam correndo o risco de insensibilização e banalização 
em relação à violência no interior da instituição, bem como desacreditando os movimentos em termos de adesão aos valores da socioeducação.

O texto Sexualidade, um direito (secundário)? Atravessamentos entre sexualidade, socioeducação e punição, escrito por Luisa Bertrami D’Angelo e Jimena de Garay Hernández, por sua vez, explora uma temática difícil e ainda controversa: o direito ao exercício da sexualidade em unidades de internação. A pesquisa foi realizada por uma equipe multidisciplinar no estado do Rio de Janeiro e abrangeu duas unidades masculinas e uma feminina, tendo se estendido de março de 2015 a outubro de 2016. A investigação indica que as regras existentes nas unidades mostram que a permissão para o exercício da sexualidade pode ser explorada de forma ambígua pelas instituições, tanto em termos de recompensa quanto de privação, e ainda esbarra em limitações estruturais e materiais. As autoras ainda salientam que a sexualidade pode aparecer na fala de socioeducadores como uma forma de "punição secundária" e até mesmo "moeda de troca" diante das condutas dos jovens.

Em Socialização legal de crianças e adolescentes: revisão da literatura e desafios de pesquisa, escrito por Herbert Rodrigues, Aline Morais Mizutani Gomes, Renan Theodoro de Oliveira, Débora Piccirillo e Rafael Cardoso de Brito, os autores abordam um tema ainda pouco explorado na Sociologia brasileira, que é a chamada socialização legal. A socialização legal nada mais seria do que o processo pelo qual os indivíduos formam noções sobre as leis, as autoridades e as instituições legais. Ao partir do pressuposto de que a socialização legal poderia ser compreendida como um campo específico de investigação, o artigo faz uma revisão da literatura no tema, sobretudo internacional, que se divide entre abordagens tradicionais (cognitivismo e aprendizagem social) e estudos mais recentes, centrados em análises sobre a legitimidade e a teoria da justiça procedimental. Estudos deste último tipo podem ser especialmente interessantes para aqueles que investigam a abordagem policial no Brasil e os seus vieses, já que os autores identificam, em sua revisão bibliográfica, algumas pesquisas que trabalharam questões semelhantes no contexto norte-americano, a partir de critérios diferentes daqueles que vêm sendo normalmente utilizados por pesquisadores aqui. Além disso, com o intuito de contribuir para um avanço dessa agenda de pesquisas em nosso país, são indicados alguns desafios que se colocam para aqueles que possam vir a se interessar pelo tema: além de eventuais desafios metodológicos, talvez o principal, identificado pelos autores, seja o de investigar como crianças e adolescentes desenvolvem compreensões sobre as leis e as autoridades em uma sociedade marcada por profundas desigualdades socioeconômicas. 
O dossiê apresenta também um conjunto expressivo de resenhas, tanto de trabalhos produzidos no Brasil, quanto de livros editados no exterior.

A primeira resenha, intitulada Estudos históricos sobre a gestão da menoridade, escrita por Fernando Salla, aborda as obras de Adriana de Resende Vianna, O mal que se advinha: polícia e menoridade no Rio de Janeiro, 1910-1920 (1999), e Elaine Marina Bueno Bernal, Arquivos do Abandono: experiências de crianças e adolescentes internados em instituições do Serviço Social de Menores de São Paulo, 1938-196o (2004). Salla traça importantes comparações entre os dois trabalhos, indicando pontos de contato e divergências entre eles, ao mesmo tempo em que deixa clara a relevância destas obras para a área de estudos que se centra sobre os adolescentes em conflito com a lei: se, em comum, ambos reforçam a importância da pesquisa histórica no tema, por outro lado, cada um dos dois trabalhos utiliza referenciais teóricos distintos (Foucault e Goffman) e tratam de contextos diversos. $\mathrm{O}$ primeiro livro analisa documentos policiais referente às duas primeiras décadas do século XX, no Rio de Janeiro, enquanto o segundo aborda o contexto de São Paulo, a partir dos anos de 1930, tendo se debruçado especificamente sobre prontuários de jovens institucionalizados.

Especialmente do trabalho de Adriana Vianna surge uma importante descoberta que foi o fato de que procedimentos policiais já mobilizavam a categoria menor antes que ela fosse institucionalmente cristalizada pelo código de 1927. Assim, as práticas policiais em voga naquele período não só foram decisivas para a conformação de um campo semântico que foi incorporado pelo antigo Código de Menores (especialmente a própria categoria menor) como essa corporação também decidia, segundo avaliações produzidas por seus membros, muitos dos destinos desses jovens: alguns eram, inclusive, enviados para residências familiares para a realização de serviços domésticos. Cabe destacar que várias dessas casas eram de policiais, o que embaralhava ainda mais as fronteiras entre as esferas do público e do privado naquele período. Eliane Bernal também aborda esta questão, mas seu foco residiu mais em realizar uma análise que conseguisse ao máximo captar as experiências vividas por estes jovens, nesses espaços institucionalizados, a partir da perspectiva dos próprios adolescentes.

Éduquer sous contrainte: une sociologie de la justice des mineurs (2016), de Nicolas Sallée, é a obra resenhada por Veridiana Domingos Cordeiro. O contexto a que se refere o livro é a França do século XX e início do XXI, tratando-se, sobretudo, de uma análise do sistema de justiça voltado para adolescentes em conflitos com a lei naquele país, ou, mais especificamente, das disputas no campo que se formou em torno desses jovens tutelados pelo Estado. O principal foco, nesse caso, é a 
Protection Judiciarie de la Jeunesse (PJJ) francesa e o papel dos educadores nesse sistema. De acordo com a autora da resenha, uma das principais constatações do autor do livro é que, a partir da década de 1990, ganharam força discursos com maior apelo punitivo, que teriam resultado, inclusive, em uma modificação na paisagem institucional do sistema em termos dos profissionais atuantes naqueles espaços. Assim, a ideia de responsabilização penal vai ganhando força, contando ainda com a criação de mais centros de educação "fechados" e de prisões para adolescentes. Interessante observar que os debates teriam chegado até mesmo a cooptar a ideia de justiça restaurativa, ${ }^{1}$ que, avessa a qualquer tipo de defesa da punição, como originalmente concebida pelo direito penal, jamais poderia servir para legitimar um movimento de recrudescimento penal, como pretenderam nesse caso.

A terceira resenha do dossiê, De imorais a superpredadoras: a criminalização das meninas nos Estados Unidos, discute o livro de Chesney-Lind e Shelden, intitulado Girls, Delinquency and Juvenile Justice (2014). A autora da resenha, Natália Bittencourt Otto, inicia seu texto destacando como é possível afirmar que com essa publicação os autores ajudaram a dar maior visibilidade para um problema que era pouco discutido na época; originalmente publicado nos Estado Unidos em 1992, a partir deste momento mais pesquisas se voltaram para as meninas criminalizadas e o livro recebeu mais quatro reedições. Em seu vigésimo aniversário, em 2014, ele foi relançado por outra editora e é esta a publicação que foi resenhada neste dossiê. Além disso, é importante destacar que o aumento significativo de detenções de adolescentes do sexo feminino nos EUA (se comparado com jovens do sexo masculino) também ajudou a que este passasse a ser um tema para novas pesquisas e alvo de debates públicos, recebendo a atenção da mídia e dos formuladores de políticas públicas.

Das ofensas de status da década de 1970, passando pela hipótese da masculinação, que foi uma explicação corrente na década de 1980, até a inclusão de fatores de caráter mais socioeconômico na década de 1990, que acarretou na ideia de superpredadoras, Chesney-Lind e Shelden tiveram como objetivo investigar a especificidade da experiência das meninas que caem nas malhas do sistema de justiça. Embora o contexto de que tratem seja o dos Estados Unidos, a autora da resenha estabelece paralelos com nosso país, mostrando o quanto pesquisas nacionais sugerem mais similitudes do que diferenças em relação ao primeiro:

1 Para um aprofundamento do tema da Justiça Restaurativa, que é um modelo alternativo de administração de conflitos que tem sido aplicado em vários países, prefencialmente para atender casos envolvendo crianças e adolescentes, ver Tonche (2015). 
são camadas e mais camadas de moralidades que se sobrepõem pela questão de gênero que atravessa o tema da punição entre crianças e adolescentes, além da vigilância sobre o corpo e sobre a sexualidade deste público alvo em particular. Além disso, outra importante constatação dos autores do livro é que embora as categorias criminais possam se alterar com o tempo (passou-se, por exemplo, de um foco nas moralidades para as violências físicas) elas não são desinstitucionalizadas, mas, de forma diferente, são reclassificadas como crimes pelas autoridades judiciais, resultando em novas formas de controle. Um exemplo importante nesse sentido são os conflitos escolares que passam a ser judicializados: brigas, ofensas, ameaças ou lesões corporais, de forma geral, não são mais toleradas como antes e passam a ser alvos de intervenção estatal (o mesmo acontecendo com conflitos familiares), tudo isto sugeriria que são as mudanças no comportamento das instituições policias e judiciais, e não no comportamento das jovens, as responsáveis pelas transformações nas estatísticas.

A quarta e última resenha deste dossiê, Criminalização, racialização e patologização: as origens do sistema de justiça juvenil da Califórnia, de Eduardo Gutierrez Cornelius, debate a obra States of Delinquency: Race and Science in the Making of California's Juvenile Justice System (2012), de Chávez-Garcia. Como o próprio título do livro sugere, a autora analisa o contexto social e as ideias que impulsionaram a formação da justiça juvenil no estado da Califórnia, no final do século XIX. Como o resenhista bem aponta, neste livro a historiadora expõe como ideias e práticas que alavancaram a formação da justiça juvenil naquele estado serviram para patologizar, segregar e esterilizar jovens considerados problemáticos, sobretudo os pertencentes a minorias raciais. Ao tecer comparações com o caso particular brasileiro, no que concerne à nossa formação de um ramo do sistema de justiça dedicado ao público infanto-juvenil, o autor da resenha destaca como o surgimento da justiça juvenil californiana se assemelha ao nosso (Alvarez, 1989), uma vez que esteve estreitamente vinculado a uma preocupação com a juventude pobre urbana, que deveria ser reformada pelo Estado. Conjugando saberes pretensamente científicos da época com práticas de reforma dos jovens californianos, as escolas de Whittier e Preston nos dão ferramentas importantes para melhor compreender como funcionava, por exemplo, a aplicação de testes de QI que objetivavam separar os adolescentes recuperáveis dos irrecuperáveis, a persistência dos castigos corporais e até mesmo o sucesso do discurso eugenista que causou a esterilização de centenas de jovens norte-americanos.

Espera-se que este conjunto de artigos e de resenhas, reunidos no presente dossiê, contribua para novas reflexões e pesquisas na área. Boa leitura! 


\section{REFERÊNCIAS BIBLIOGRÁFICAS}

Alvarez, Marcos César. A emergência do código de menores de 1927: uma análise do discurso jurídico e institucional da assistência e proteção aos menores. Dissertação (Mestrado em Sociologia). São Paulo: Faculdade de Filosofia, Letras e Ciências Humanas, Universidade de São Paulo, 1989.

Adorno, Sérgio. “A experiência precoce da punição". In: Martins, José de Souza (org.) $O$ massacre dos inocentes: as crianças sem infância no Brasil. São Paulo: Hucitec, 1993, p. 181-208.

BARreto, Tobias. Menores e loucos e fundamentos do direito de punir. Rio de Janeiro: Empresa Graphica Editora de Paulo, Pongetti \& C, 1926.

CEBrap - CENTRO BRASILEIRO DE ANÁLISE E PLANEJAMENTO. A CRIANÇA, o adolescente, a cidade. São Paulo: CEPRAP, 1972.

Passetti, Edson. Política nacional do bem-estar do menor. Dissertação (Mestrado em Ciências Sociais). São Paulo: Pontifícia Universidade Católica de São Paulo, 1982.

PAula, Liana de. Liberdade assistida: punição e cidadania na cidade de São Paulo. Tese (Doutorado em Sociologia). São Paulo: Faculdade de Filosofia, Letras e Ciências Humanas, Universidade de São Paulo, 2011.

Rızzını, Irene; Rızzını, Irma. A institucionalização de crianças no Brasil: percurso histórico e desafios do presente. Rio de Janeiro: Editora PUC-Rio; São Paulo: Loyola, 2004.

Tonche, Juliana. A construção de um modelo "alternativo" de gestão de conflitos: usos e representações de justiça restaurativa no estado de São Paulo. Tese (Doutorado em Sociologia). São Paulo: Faculdade de Filosofia, Letras e Ciências Humanas, Universidade de São Paulo, 2015. 